Article

\title{
Temperature-Induced Reversible and Irreversible Transitions between Metastable Perovskite Phases in the $\mathrm{BiFe}_{1-y} \mathrm{Sc}_{y} \mathrm{O}_{3}$ Solid Solutions
}

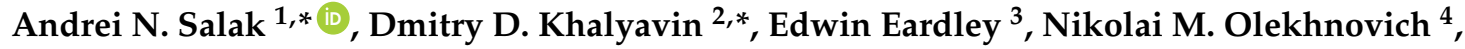 \\ Anatoli V. Pushkarev ${ }^{4}$, Yury V. Radyush ${ }^{4}$, Aleksandr D. Shilin ${ }^{5}$ and Vasili V. Rubanik ${ }^{5}$ \\ 1 Department of Materials and Ceramic Engineering and CICECO-Aveiro Institute of Materials, \\ University of Aveiro, Aveiro 3810-193, Portugal \\ 2 ISIS Facility, Rutherford Appleton Laboratory, Chilton, Didcot OX11 0QX, UK \\ 3 Element Six UK Ltd., Global Innovation Centre, Harwell Oxford, Didcot OX11 0QR, UK; \\ edwin.eardley@e6.com \\ 4 Scientific-Practical Materials Research Centre of NAS of Belarus, P. Brovka Street, 19, Minsk 220072, Belarus; \\ olekhnov@ifttp.bas-net.by (N.M.O.); pushk@ifttp.bas-net.by (A.V.P.); radyush@ifttp.bas-net.by (Y.V.R.) \\ 5 Institute of Technical Acoustics of NAS of Belarus, Lyudnikov Avenue, 13, Vitebsk 210023, Belarus; \\ ale53@bk.ru (A.D.S.); ita@vitebsk.by (V.V.R.) \\ * Correspondence: salak@ua.pt (A.N.S.); dmitry.khalyavin@stfc.ac.uk (D.D.K.); \\ Tel.: +351-234-247318 (A.N.S.); +44-1235-446910 (D.D.K.)
}

Received: 18 January 2018; Accepted: 8 February 2018; Published: 10 February 2018

\begin{abstract}
The antipolar orthorhombic Pnma phase with the $\sqrt{2} a_{p} \times 4 a_{p} \times 2 \sqrt{2} a_{p}$ superstructure $\left(a_{p} \sim 4 \AA\right.$ is the pseudocubic perovskite unit-cell parameter) is observed in many perovskite compositions derived from $\mathrm{BiFeO}_{3}$. Temperature-induced structural transformations in metastable perovskite solid solutions with the Pnma structure corresponding to the range of $0.30 \leq y \leq 0.60$ of the $(1-y) \mathrm{BiFeO}_{3}-y \mathrm{BiScO}_{3}$ quasi binary system were studied using temperature $\mathrm{X}$-ray and neutron powder diffraction. These compositions cannot be prepared in bulk form at ambient pressure but can be stabilized in the Pnma phase by means of quenching after synthesis under high pressure. The compositions were investigated in situ between $1.5 \mathrm{~K}$ and the temperature of the stability limit of their metastable phases (about 870-920 K). It has been found that heating the as-prepared compositions with the Pnma phase leads to formation of the rhombohedral R3c phase $\left(\sqrt{2} a_{p} \times \sqrt{2} a_{p} \times 2 \sqrt{3} a_{p}\right)$, which, on cooling down to room temperature, either remains or transforms into a polar orthorhombic Ima 2 phase $\left(2 a_{p} \times \sqrt{2} a_{p} \times \sqrt{2} a_{p}\right)$. The observed phase transformations in the $\mathrm{BiFe}_{1-y} \mathrm{Sc}_{y} \mathrm{O}_{3}$ perovskite series on heating and on cooling are considered in terms of geometrical factors.
\end{abstract}

Keywords: metastable phase; high-pressure synthesis; perovskite; polymorphism

\section{Introduction}

Perovskite multiferroics based on chemically modified bismuth ferrite attract great attention in respect to both fundamental research and practical application $[1,2]$. While the conventional preparation methods are generally applicable to obtain bulk polycrystalline samples with the entire range of the Bi-site substitutions, a wide range of Fe-site substitutions are possible under high pressure only. The high-pressure synthesis technique offers unique opportunities to obtain new phases but requires complicated and expensive equipment. Besides, a sample obtained as a result of one high-pressure high-temperature run, is rather small. In cases when the required pressure is above $\sim 8 \mathrm{GPa}$, the obtained amounts are hardly enough, even for the crystal structure characterization. The cases when researchers managed to measure dielectric properties of the high-pressure synthesized ceramics are rather rare [3-7]. 
The metastable perovskites with the 1:1 ratio of $\mathrm{Fe}^{3+}$ to the substituting $B^{3+}$ cation are the most studied [8-11]. Generally speaking, the compositional ranges of interest where new phases or phases with adjusted properties occur are usually beyond the $\mathrm{BiFe}_{0.50} B^{3+}{ }_{0.50} \mathrm{O}_{3}$ formula. However, there are only a few entire series of $\mathrm{BiFeO}_{3}-\mathrm{Bi}^{3+} \mathrm{O}_{3}$ solid solutions have been prepared under high pressure [12-14].

Among the structural phases found in the $\mathrm{BiFeO}_{3}$-based perovskite solid solutions, one of the most interesting phases appears to be the antipolar orthorhombic Pnma with the $\sqrt{2} a_{p} \times \sqrt{2} a_{p} \times 2 \sqrt{3} a_{p}$ superstructure (where $a_{p} \sim 4 \AA$ is the pseudocubic perovskite unit-cell parameter). The antipolar Pnma phase is observed in the perovskite solid solutions prepared using conventional methods $\left((\mathrm{Bi}, \mathrm{La}) \mathrm{FeO}_{3}[15],(\mathrm{Bi}, \mathrm{Nd}) \mathrm{FeO}_{3}[16,17]\right)$, and the high pressure synthesis $\left(\mathrm{Bi}(\mathrm{Fe}, \mathrm{Mn}) \mathrm{O}_{3}[12,18]\right)$. The characteristic feature of this antipolar structure is a rather interesting rotational (tilting) octahedra pattern of the ++-- type, where " + " and "-" indicate in-phase and out-of-phase rotations of the oxygen octahedra about the $[010]_{p}$ axis, respectively.

The most complete series of the $(1-y) \mathrm{BiFeO}_{3}-y \mathrm{BiScO}_{3}$ solid solutions has recently been synthesized under high-pressure [19]. The compositional range of the metastable antipolar Pnma phase is rather wide, namely between about $y=0.30$ and $y=0.60$. The thermal stability limits of these compositions were estimated to be in the range of $920-870 \mathrm{~K}$ when $0.30 \leq y \leq 0.60$, respectively. The stability limit is defined as a temperature that is $50 \mathrm{~K}$ lower than that of the irreversible decomposition accompanied by the formation of non-perovskite phase(s).

To date, the most studied composition of the $\mathrm{BiFe}_{1-y} \mathrm{Sc}_{y} \mathrm{O}_{3}$ series is that, corresponding to $y=0.50$ [11]. It was revealed that two nonequivalent structures with the same Pnma space group are possible for $\mathrm{BiFe}_{0.50} \mathrm{Sc}_{0.50} \mathrm{O}_{3}[11,20]$. In addition, an annealing-stimulated polymorphic transformation has been found. The antipolar Pnma phase in the as-prepared (non-annealed) $\mathrm{BiFe}_{0.50} \mathrm{Sc}_{0.50} \mathrm{O}_{3}$ sample was observed to transform irreversibly into the polar $R 3 c$ phase when heated. The latter then transforms reversibly into the polar Ima2 phase when cooled. The Ima2 polymorph of $\mathrm{BiFe}_{0.50} \mathrm{Sc}_{0.50} \mathrm{O}_{3}$ demonstrates the complex polar structure and represents one of the rare examples of canted ferroelectrics [11]. It is a great advantage that two different perovskite polymorphs of the same composition are available for any comparative study in the same wide temperature range, which includes room temperature.

For the $\mathrm{BiFe}_{0.50} \mathrm{Sc}_{0.50} \mathrm{O}_{3}$ composition, the competing phases are those with the antipolar Pnma, the polar R3c, and the polar Ima2 structures. As a part of the systematic study of perovskite phases of the $\mathrm{BiFe}_{1-y} \mathrm{Sc}_{y} \mathrm{O}_{3}$, the relations between these (and probably other) phases in compositions from a wider range of the iron-to-scandium substitutions, namely in the range of $0.30 \leq y \leq 0.60$, were considered.

In this paper, we report on the temperature behaviour of the metastable perovskite phases of the $\mathrm{BiFe}_{1-y} \mathrm{Sc}_{y} \mathrm{O}_{3}$ series studied using in situ powder X-ray and neutron diffraction. The revealed phase transformations were compared with those observed in other metastable solid solutions derived from $\mathrm{BiFeO}_{3}$.

\section{Materials and Methods}

High-purity $\mathrm{Bi}_{2} \mathrm{O}_{3}, \mathrm{Fe}_{2} \mathrm{O}_{3}$, and $\mathrm{Sc}_{2} \mathrm{O}_{3}$ were used as starting reagents to prepare the following compositions of the $\mathrm{BiFe}_{1-y} \mathrm{Sc}_{y} \mathrm{O}_{3}$ series: $y=0.30,0.40,0.45,0.50,0.55$, and 0.60 . The oxides were mixed in the stoichiometric ratio, ball-milled in ethanol, dried, and pressed into pellets. The pellets were heated in a closed alumina crucible at $1040 \mathrm{~K}$ for $10 \mathrm{~min}$ followed by quenching in air. The obtained material served as a precursor for the high pressure synthesis.

High pressure was generated using a hydraulic anvil press DO-138A (with a press capacity of $6300 \mathrm{kN}$ ) equipped with a Bridgman-type apparatus (Tyazhpressmash, Ryazan, Russia). The samples were synthesized at $6 \mathrm{GPa}$ and $1370-1470 \mathrm{~K}$ for 1-2 min. In order to avoid the penetration of graphite from the tubular heater to the sample, a protective screen of molybdenum foil was used. For further analyses, the obtained ceramics were reduced to powders.

An X-ray diffraction (XRD) study of the powders was performed using a PANalytical X'Pert MPD $\mathrm{PRO}$ diffractometer (Ni-filtered $\mathrm{Cu}$ Ka radiation, $\mathrm{PIX}_{\mathrm{X}} \mathrm{l}^{1 \mathrm{D}}$ detector, and an exposition corresponding to 
about $2 \mathrm{~s}$ per step of $0.02^{\circ}$ over the angular range of $15-100^{\circ}$, Almelo, Netherlands) at room temperature. In situ XRD measurements were conducted in an Anton Paar high-temperature chamber (HTK 16N) in a temperature range between 300 and $920 \mathrm{~K}$. A dwell time before the XRD data collecting at each temperature point was $30 \mathrm{~min}$.

Neutron powder diffraction data were collected at the ISIS pulsed neutron and muon facility of the Rutherford Appleton Laboratory (UK) on the WISH diffractometer located at the second target station [21]. The sample was loaded into a cylindrical 3-mm-diameter vanadium can and measured in a temperature range of 1.5-300 K, with the exposition time of $0.5 \mathrm{~h}$ using an Oxford Instruments cryostat (Abington, UK).

Rietveld refinements of the crystal (from both X-ray and neutron diffraction data) and magnetic structures (from neutron diffraction data) were performed using the FULLPROF program [22]. In the refinement procedure, the nominal cation compositions were fixed with $\mathrm{Bi}$ and $\mathrm{Sc} / \mathrm{Fe}$ located in the $A$ - and $B$-site perovskite positions, respectively. Some trial refinements with unfixed cation occupancies were also performed to explore possible deviations from the nominal chemical compositions. No statistically significant deviations were revealed, confirming the nominal chemical content and the cation distribution in the studied samples.

\section{Results and Discussion}

As mentioned in the introduction, the heating/cooling thermal cycle of the as-prepared $\mathrm{BiFe}_{0.50} \mathrm{Sc}_{0.50} \mathrm{O}_{3}$ results in transformation from the antipolar orthorhombic polymorph to the polar orthorhombic phase via formation of the intermediate high-temperature rhombohedral phase [11]. Figure 1 shows the most representative ranges of the temperature XRD patterns of $\mathrm{BiFe}_{0.50} \mathrm{Sc}_{0.50} \mathrm{O}_{3}$. Upon heating, the antipolar orthorhombic Pnma phase of $\mathrm{BiFe}_{0.50} \mathrm{Sc}_{0.50} \mathrm{O}_{3}$ is the only phase up to about $720 \mathrm{~K}$. This orthorhombic phase coexists with the rhombohedral $R 3 c$ phase until about $770 \mathrm{~K}$. At higher temperatures, only the rhombohedral phase is observed (Figure 1a). Upon cooling, the polar orthorhombic phase appears at about $670 \mathrm{~K}$. Below $570 \mathrm{~K}$, the R3c-to-Ima2 transformation is complete (Figure 1b).
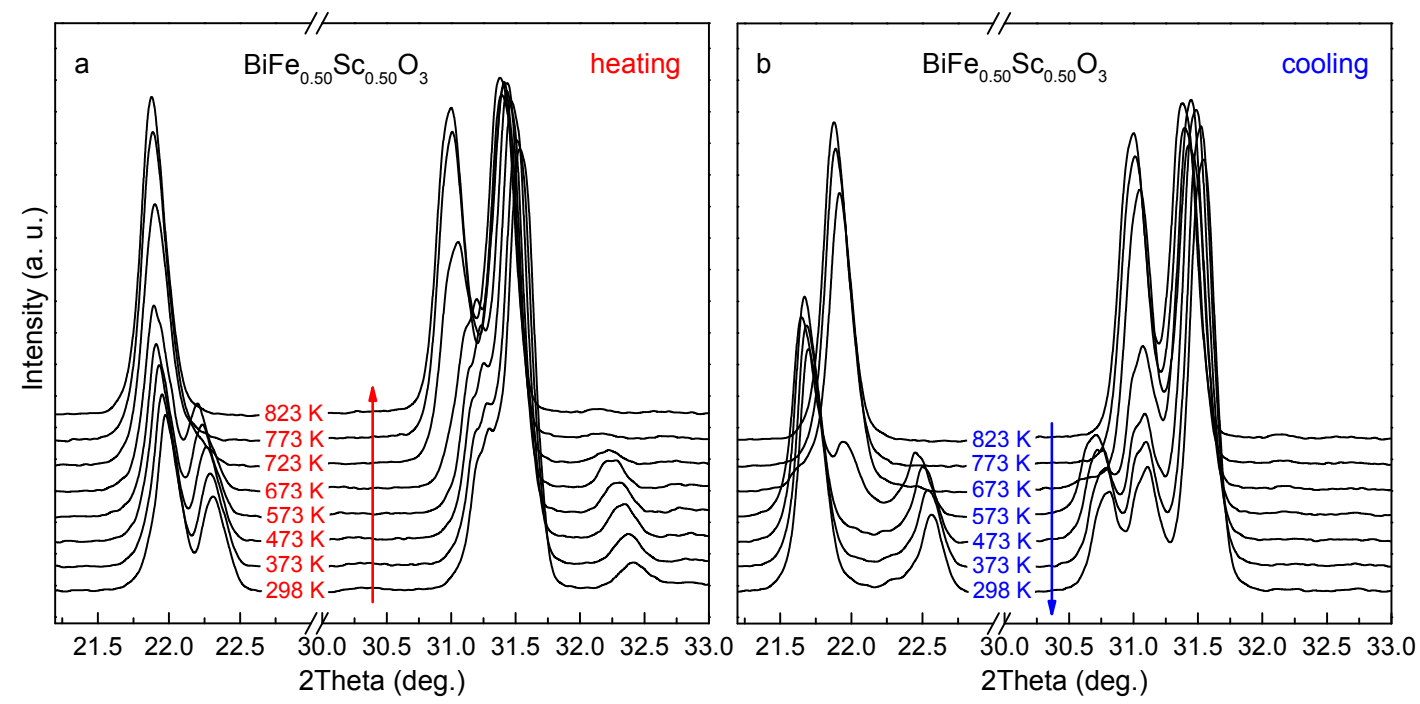

Figure 1. The most representative ranges of the XRD patterns of the as-prepared $\mathrm{BiFe}_{0.50} \mathrm{Sc}_{0.50} \mathrm{O}_{3}$ perovskite at the first thermal cycle: (a) on heating up to $873 \mathrm{~K}$ and (b) on cooling down to room temperature.

It should be pointed out that the polar atomic displacements in both the rhombohedral and orthorhombic phases are sufficiently large, even at high temperatures to be reliably detected from the available XRD patterns. Refinements of the data using the centrosymmetric counterparts $R \overline{3} c$ 
and Imma resulted in an unacceptable fitting quality and could be safely ruled out. Irreversible annealing-stimulated transformations Pnma-to-R3c and $C 2 / c$-to-Pnma were previously observed in the metastable perovskites $\mathrm{BiFe}_{0.75} \mathrm{Mn}_{0.25} \mathrm{O}_{3}$ [18] and $\mathrm{BiGa}_{1-x} \mathrm{Cr}_{x} \mathrm{O}_{3}(0.70 \leq x \leq 0.90)$ [14], respectively. In these systems, however, the transformations are direct without formation of any intermediate high-temperature phase(s).

The second and all of the following heating/cooling thermal cycles, with maximum temperature not exceeding $920 \mathrm{~K}$, demonstrated that the transition between the Ima 2 phase and the R3c phase in $\mathrm{BiFe}_{0.50} \mathrm{Sc}_{0.50} \mathrm{O}_{3}$ is reversible. The $R 3 c$ phase appears at about $570 \mathrm{~K}$ and disappears at $500 \mathrm{~K}$, while the orthorhombic Ima2 phase disappears at about $720 \mathrm{~K}$ and appears again at about $670 \mathrm{~K}$ (Figure 2).

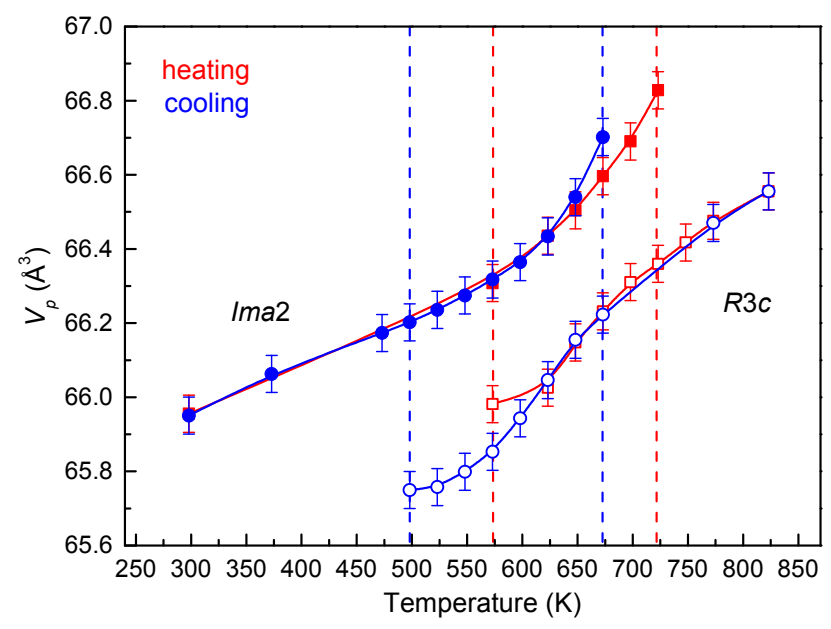

Figure 2. Temperature dependence of the normalized unit-cell volume of the $\mathrm{BiFe}_{0.50} \mathrm{Sc}_{0.50} \mathrm{O}_{3}$ perovskite at the second thermal cycle: the Ima2 phase (solid symbols) and the $R 3 c$ phase (open symbols).

In the XRD patterns of the in situ studied $\mathrm{BiFe}_{0.70} \mathrm{Sc}_{0.30} \mathrm{O}_{3}$ ceramics, regular changes in both the shape and the intensity ratio of the fundamental reflections, suggesting an onset of an $R 3 \mathrm{c}$ phase, were observed to appear between $380 \mathrm{~K}$ and $400 \mathrm{~K}$ (Figure 3a). The transformation was complete at about $470 \mathrm{~K}$ : no traces of the parent Pnma phase were observed above this temperature. The transformation was irreversible since the rhombohedral symmetry of the annealed $\mathrm{BiFe}_{0.70} \mathrm{Sc}_{0.30} \mathrm{O}_{3}$ sample remains when the sample is cooled down to room temperature (Figure $3 b$ ).
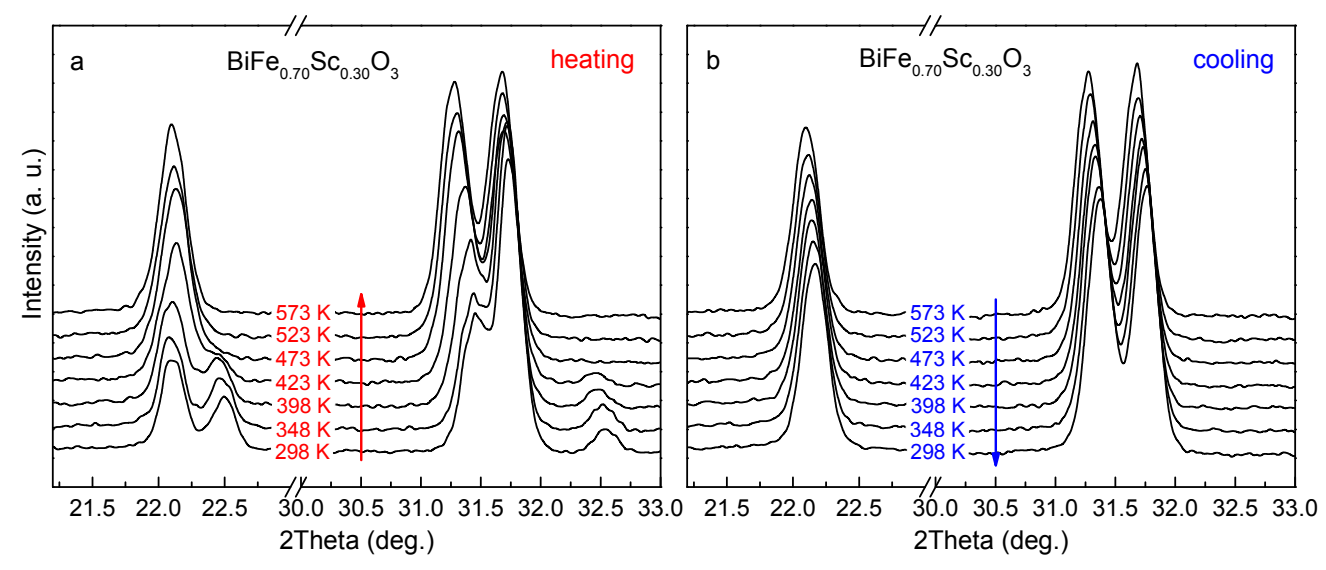

Figure 3. The most representative ranges of the $\mathrm{XRD}$ patterns of the as-prepared $\mathrm{BiFe}_{0.70} \mathrm{Sc}_{0.30} \mathrm{O}_{3}$ perovskite at the first thermal cycle: (a) upon heating to $923 \mathrm{~K}$ and (b) upon cooling to room temperature. 
Although the annealing-stimulated transition from the antipolar Pnma phase to the polar $\mathrm{R} 3 \mathrm{c}$ phase observed in $\mathrm{BiFe}_{0.70} \mathrm{Sc}_{0.30} \mathrm{O}_{3}$ is very similar to that reported for the high-pressure prepared $\mathrm{BiFe}_{0.75} \mathrm{Mn}_{0.25} \mathrm{O}_{3}$ [18], it should be noted that the $R 3 c$ phase of $\mathrm{BiFe}_{0.75} \mathrm{Mn}_{0.25} \mathrm{O}_{3}$ is stable (i.e., it can be prepared via conventional synthesis at ambient pressure), while both the Pnma and the $R 3 c$ phases of $\mathrm{BiFe}_{0.70} \mathrm{Sc}_{0.30} \mathrm{O}_{3}$ are metastable [19].

In the as-prepared $\mathrm{BiFe}_{0.70} \mathrm{Sc}_{0.30} \mathrm{O}_{3}$ and $\mathrm{BiFe}_{0.50} \mathrm{Sc}_{0.50} \mathrm{O}_{3}$, the annealing-stimulated transformations are complete. The annealed samples are single-phase-the rhombohedral $R 3 c$ and the orthorhombic Ima2, respectively.

As can be seen in Figure 4a, in the sample with the intermediate composition (with the relative scandium content $y=0.40$ ), the sequence of phase transformations and phase coexistence is qualitatively the same as that in the samples, with compositions corresponding to $y=0.30$ and $y=0.50$. An increase in temperature leads to the formation of the rhombohedral $R 3 c$ phase that coexists with the parent orthorhombic Pnma phase in some temperature range. Above about $550 \mathrm{~K}$, the rhombohedral phase is only observed. However, the R3c-to-Ima2 transformation on cooling is incomplete: the annealed sample at room temperature was found to be a mixture of the rhombohedral and the orthorhombic phases (Figure $4 \mathrm{~b}$ ). The consecutive thermal cycles with the maximum temperature not exceeding the thermal stability limit of the perovskite $\mathrm{BiFe}_{0.60} \mathrm{Sc}_{0.40} \mathrm{O}_{3}[19]$ resulted in no change in the ratio of the $R 3 c$ and Ima2 phases in the annealed sample at room temperature.

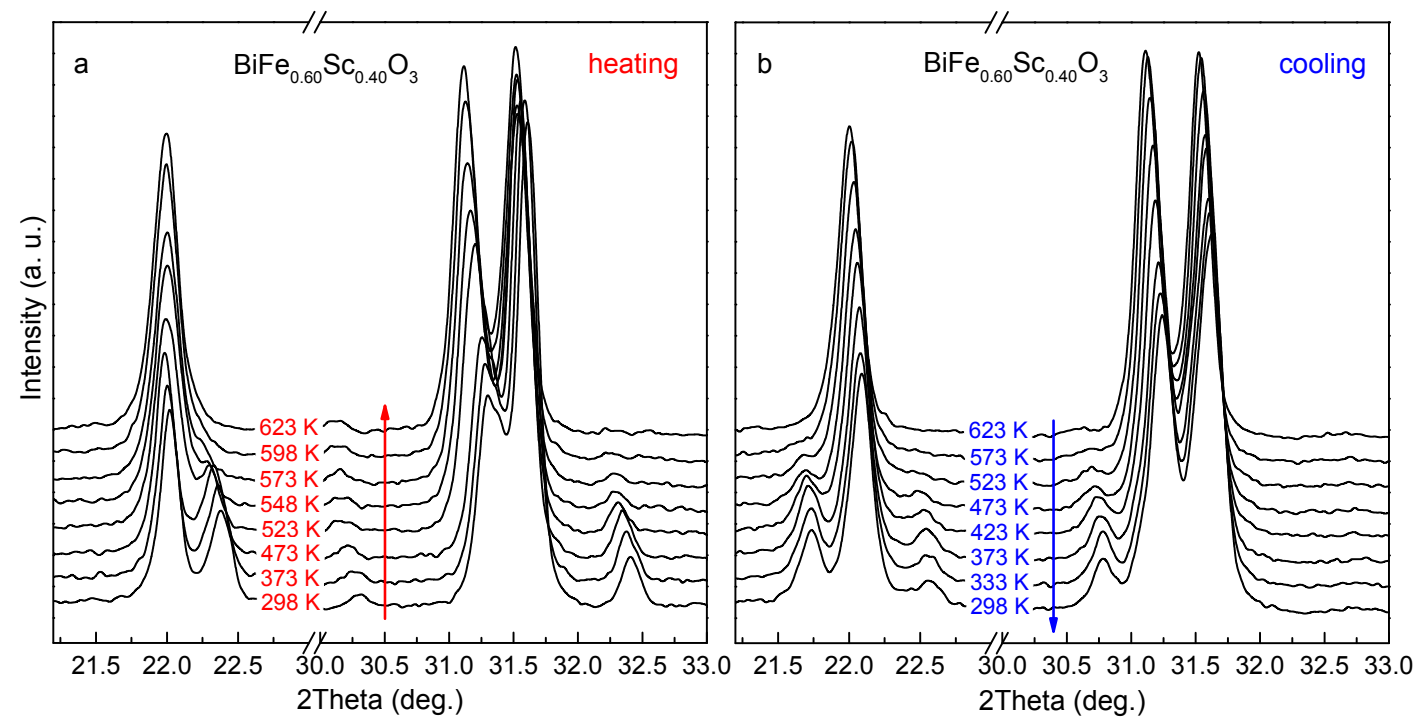

Figure 4. The most representative ranges of the XRD patterns of the as-prepared $\mathrm{BiFe}_{0.60} \mathrm{Sc}_{0.40} \mathrm{O}_{3}$ perovskite at the first thermal cycle: (a) upon heating to $923 \mathrm{~K}$ and (b) upon cooling to room temperature.

In the $\mathrm{BiFe}_{0.55} \mathrm{Sc}_{0.45} \mathrm{O}_{3}$ composition, the transformations from the parent orthorhombic phase into the rhombohedral phase upon heating and from the rhombohedral phase into the polar orthorhombic phase upon cooling both begin at higher temperatures than those of the respective transformations in $\mathrm{BiFe}_{0.60} \mathrm{Sc}_{0.40} \mathrm{O}_{3}$; however, the temperature behaviours of these compositions with $y=0.45$ and $y=0.40$ are the same in general. At room temperature, the annealed $\mathrm{BiFe}_{0.55} \mathrm{Sc}_{0.45} \mathrm{O}_{3}$ samples represented a mixture of the $R 3 \mathrm{c}$ and Ima 2 phases as well. The relative stabilities of these phases were particularly studied. The two-phase perovskite samples were obtained by means of either quenching or slow cooling from the temperature range where the only structural phase is the rhombohedral phase. Figure 5 demonstrates the XRD patterns of the quenched and the slow-cooled $\mathrm{BiFe}_{0.60} \mathrm{Sc}_{0.40} \mathrm{O}_{3}$ samples. It can be seen that the relative amount of the Ima2 phase in the slow-cooled sample is slightly higher than that in the quenched sample, although the difference is rather negligible. 


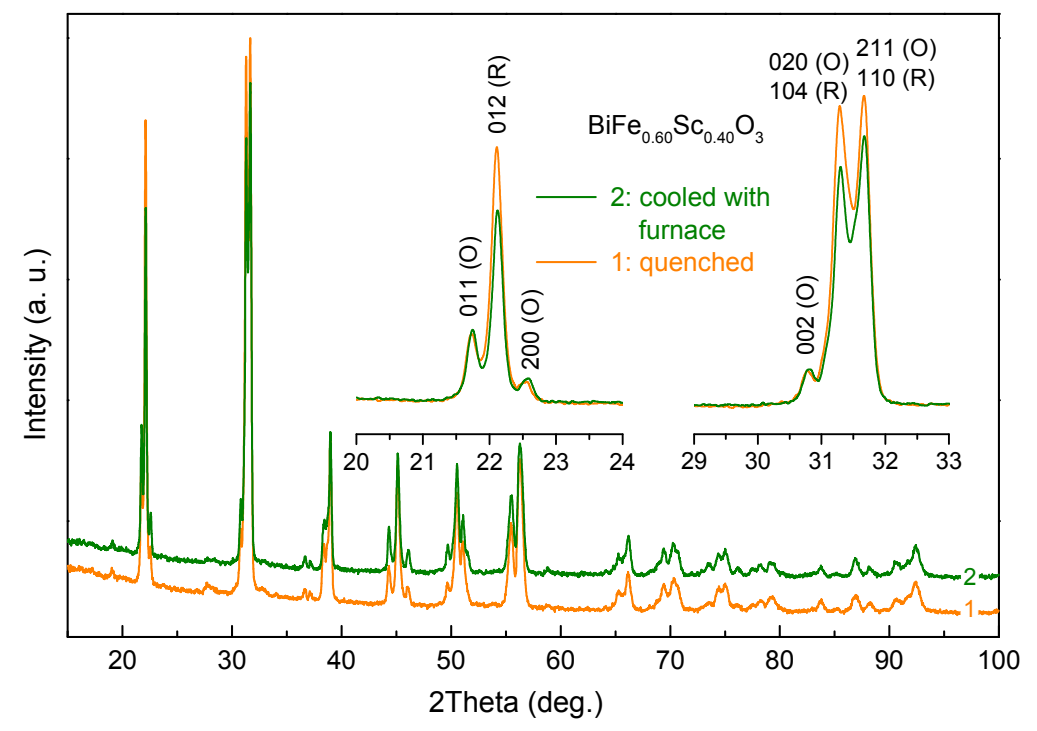

Figure 5. XRD patterns of the $\mathrm{BiFe}_{0.60} \mathrm{Sc}_{0.40} \mathrm{O}_{3}$ perovskite at room temperature after 4-h of annealing at $873 \mathrm{~K}$ followed by either quenching or slow cooling with a furnace. The cooling rate was $\leq 1 \mathrm{~K} / \mathrm{min}$. The insets show the most representative ranges of the XRD patterns, with the diffraction reflections of the rhombohedral $R 3 c$ phase $(\mathrm{R})$ and the orthorhombic Ima2 phase $(\mathrm{O})$ indicated.

In the studied $\mathrm{BiFe}_{1-y} \mathrm{Sc}_{y} \mathrm{O}_{3}$ perovskites with the compositions corresponding to $y=0.40$ and $y=0.45$, a transformation of the rhombohedral phase into the polar orthorhombic phase upon cooling starts at a relatively low temperature and slows down fast as temperature decreases. Therefore, the observed phase ratio in the annealed sample at room temperature is almost independent on the cooling rate.

The behaviour of the $R 3 c+\operatorname{Ima} 2$ mixture in the annealed $\mathrm{BiFe}_{0.60} \mathrm{Sc}_{0.40} \mathrm{O}_{3}$ samples below room temperature was also studied using neutron diffraction. It was found that both the $R 3 \mathrm{c}$ and Ima2 phases and their ratio remain without any change down to $1.5 \mathrm{~K}$. The as-prepared $\mathrm{BiFe}_{0.60} \mathrm{Sc}_{0.40} \mathrm{O}_{3}$ and $\mathrm{BiFe}_{0.50} \mathrm{Sc}_{0.50} \mathrm{O}_{3}$ were studied as well at the same conditions. No transformation of the antipolar orthorhombic phase was observed. Thus, both the as-prepared perovskite phase and that obtained as a result of the heating/cooling thermal cycling are stable upon cooling to below room temperature. The refinement of the neutron diffraction data required also the inclusion of the long-range $G$-type of antiferromagnetic ordering in all three phases with the R3c, Ima2 and Pnma space groups. The magnetic structure of the single phase as-prepared $\mathrm{BiFe}_{0.60} \mathrm{Sc}_{0.40} \mathrm{O}_{3}$ was found to be identical to the spin ordering reported in the isostructural $\mathrm{BiFe}_{0.50} \mathrm{Sc}_{0.50} \mathrm{O}_{3}$ perovskite (the spins are along the $b$-axis) [11]. Crystallographic directions of the spins in the phase-mixed annealed $\mathrm{BiFe}_{0.60} \mathrm{Sc}_{0.40} \mathrm{O}_{3}$ sample, however, could not be concluded unambiguously from the available diffraction data.

It was found that the transition from the parent Pnma phase of the $\mathrm{BiFe}_{0.45} \mathrm{Sc}_{0.55} \mathrm{O}_{3}$ composition to the rhombohedral $R 3 c$ phase upon heating begins at a relatively high temperature and is not completed at the decomposition temperature of the perovskite phases (Figure 6a). The Pnma phase that was not transformed upon heating was observed to remain untransformed when cooled, while the high-temperature $R 3 c$ phase entirely transformed into the Ima 2 phase between about 670 and $600 \mathrm{~K}$ (Figure 6b). Attempts to complete the Pnma-to-R3c transformation in the following thermal cycles were unsuccessful. 

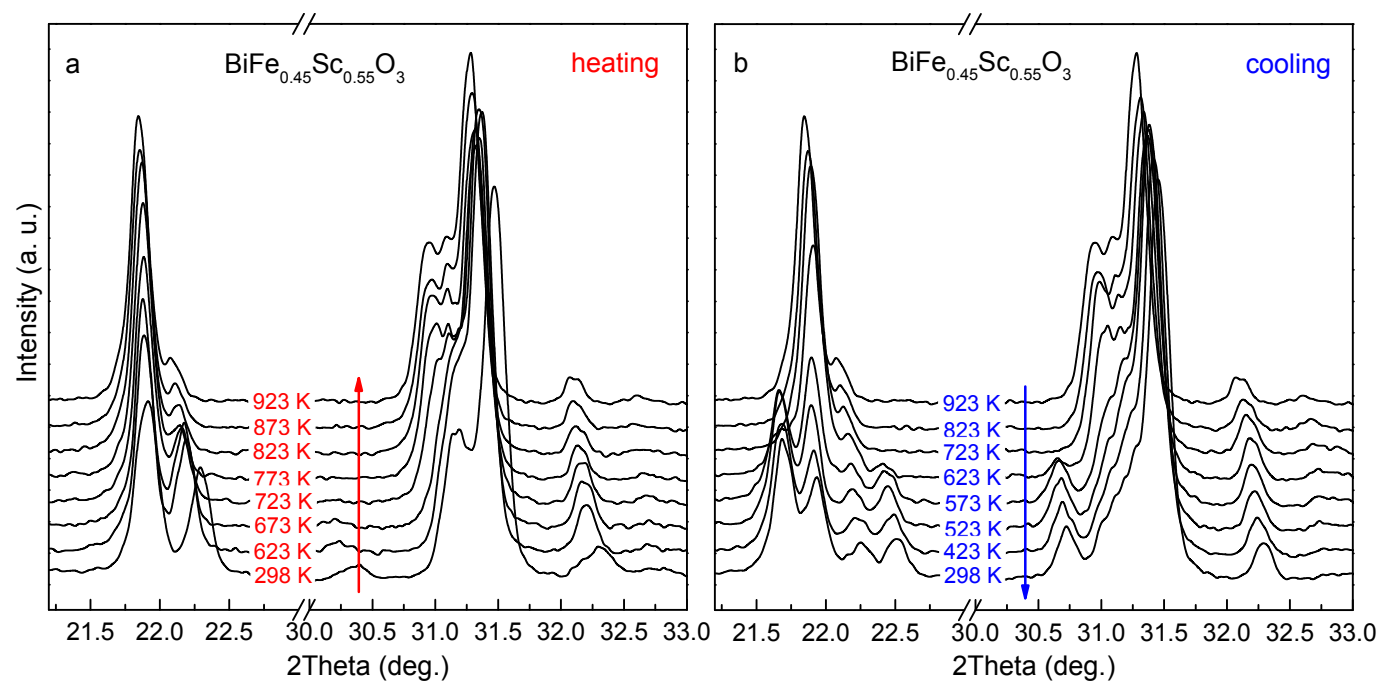

Figure 6. The most representative ranges of the XRD patterns of the as-prepared $\mathrm{BiFe}_{0.45} \mathrm{Sc}_{0.55} \mathrm{O}_{3}$ perovskite at the first thermal cycle: (a) upon heating to $923 \mathrm{~K}$ and (b) upon cooling to room temperature.

In the case of the $\mathrm{BiFe}_{0.40} \mathrm{Sc}_{0.60} \mathrm{O}_{3}$ composition, no sign of phase transition was observed upon either heating or cooling. The parent Pnma phase was the only structural phase observed until the decomposition temperature was reached.

Based on the data of the in situ temperature XRD study, a tentative state diagram of the $\mathrm{BiFe}_{1-y} \mathrm{Sc}_{y} \mathrm{O}_{3}$ series in the range of $0.30 \leq y \leq 0.60$, where the as-prepared phase is the antipolar orthorhombic phase, was suggested (Figure 7). The right part of the diagram indicates the irreversible Pnma-to-R3c transitions (both complete and incomplete), while the transitions shown in the left part are all reversible.

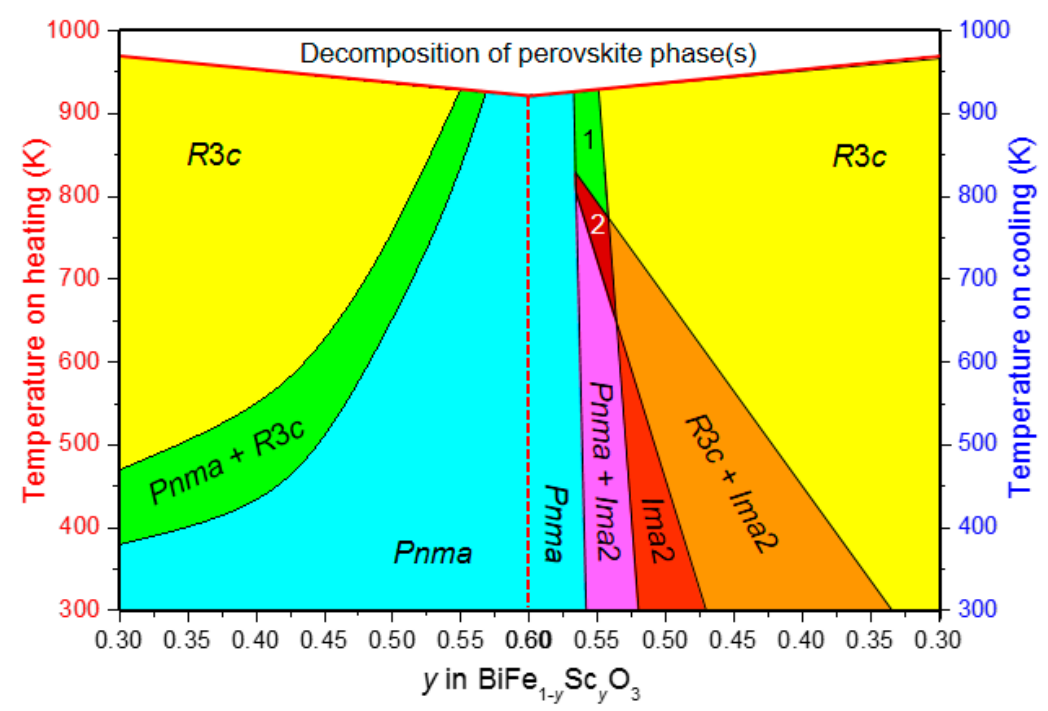

Figure 7. Tentative state diagram of the metastable perovskites of the $\mathrm{BiFe}_{1-y} \mathrm{Sc}_{y} \mathrm{O}_{3}$ series $(0.30 \leq y \leq 0.60)$ in the compositional range of $0.30 \leq y \leq 0.60$ upon heating to their temperature stability limit (the left half of the graph) and upon subsequent cooling (the right half of the graph). The areas marked as 1 and 2 correspond to the Pnma +R3c phase mixture and the Pnma $+R 3 c+I m a 2$ phase mixture, respectively. 
We would like to stress that all the perovskite phases studied in this work are metastable and decompose when annealing above their temperature stability limits, which are in the range of 920-870 $\mathrm{K}$ when $\mathrm{y}$ is between 0.30 and 0.60 , respectively [19]. However, this range is well above the operating ranges of the majority of electronic devices. Therefore, materials based on the metastable perovskite phases of the $\mathrm{BiFe}_{1-y} \mathrm{Sc}_{y} \mathrm{O}_{3}$ series have a potential for application. A remarkable feature of this perovskite system is that the pattern of the state diagram is dependent on the maximum temperature in the first thermal cycle. By means of controlled annealing, materials with different combinations of the perovskite phases can be obtained. This feature of metastable perovskites could be used, e.g., for the creation of new materials with a morphotropic phase boundary.

It should be noted that the antipolar orthorhombic Pnma phase and the polar rhombohedral $R 3 \mathrm{c}$ phase are always observed in $\mathrm{BiFeO}_{3}$-derived solid solutions, while the metastable polar orthorhombic Ima2 phase was found in the $\mathrm{BiFe}_{1-y} \mathrm{Sc}_{y} \mathrm{O}_{3}$ system only. In other single-phase perovskite solid solutions prepared so far, using a high-pressure synthesis, iron was substituted either by the cations of transition metals $\left(\mathrm{Mn}^{3+}[10,12,18], \mathrm{Co}^{3+}[13,23], \mathrm{Cr}^{3+}\right.$ [9]) with an ionic size similar to that of $\mathrm{Fe}^{3+}$ or by $\mathrm{Ga}^{3+}[14]$, whose size is $8 \%$ smaller. The peculiarity of the $\mathrm{BiFe}_{1-y} \mathrm{Sc}_{y} \mathrm{O}_{3}$ perovskite series is that the ionic size of $\mathrm{Sc}^{3+}$ is $24 \%$ greater than that of $\mathrm{Fe}^{3+}$. One can suppose that the onset of the Ima2 phase, which has a reduced unit-cell volume that is greater than those of the Pnma and $R 3 c$ phases in a particular $\mathrm{BiFe}_{1-y} \mathrm{Sc}_{y} \mathrm{O}_{3}$ composition at the same temperature, is associated with the geometrical factor (negative chemical pressure). Hence, one can suggest that new polar phases such as the Ima2 phase can be induced in other $\mathrm{BiFeO}_{3}$-derived metastable solid solutions, in which $\mathrm{Fe}^{3+}$ is substituted by $B^{3+}$ cations or by combinations of cations, such as $\left(B^{2+} 1 / 2 B^{4+} 1 / 2\right)$, whose (average) cation size is bigger than that of iron. Such solid solutions certainly require a high-pressure synthesis. The temperature stability limit of the metastable phases can be expected to correlate with the substitution rate: a greater substituting cation induces a faster compositional decrease in the stability limit. Therefore, the chances of obtaining a new phase via annealing-stimulated irreversible transformation will decrease as the substitution rate increases.

\section{Conclusions}

The perovskite compositions of the $\mathrm{BiFe}_{1-y} \mathrm{Sc}_{y} \mathrm{O}_{3}$ series $(0.30 \leq y \leq 0.60)$ prepared using a high-pressure synthesis are orthorhombic with the antipolar Pnma structure. The Pnma phases are metastable and transform into other metastable phases(s) during the heating/cooling thermal cycling, where the maximum temperature does not exceed thermal stability limits. Such an annealing of the composition with $y=0.30$ results in an irreversible transformation of the orthorhombic Pnma phase into the rhombohedral $R 3 c$ phase. In the case of the compositions from the range of $0.40 \leq y \leq 0.50$, the high-temperature $R 3 c$ phase formed when heated undergoes a phase transition to the polar orthorhombic Ima2 phase. Both phases coexist in some temperature ranges. In the $\mathrm{BiFe}_{0.50} \mathrm{Sc}_{0.50} \mathrm{O}_{3}$ composition, the R3c-to-Ima 2 transformation that occurs when cooled is complete below $\sim 570 \mathrm{~K}$, while the annealed compositions with $y=0.40$ and $y=0.45$ constitute mixtures of the rhombohedral and the polar orthorhombic phases at room temperature and at down to $1.5 \mathrm{~K}$. Transformations from the as-prepared antipolar Pnma phase into the high-temperature $R 3 c$ phase in the composition with $y=0.55$ upon heating is not complete, and the annealed sample represents a mixture of the Pnma phase and the Ima2 phase. For the $\mathrm{BiFe}_{0.40} \mathrm{Sc}_{0.60} \mathrm{O}_{3}$ composition, the heating/cooling cycles with the maximum temperature up to $920 \mathrm{~K}$ induce no phase transformation.

A tentative state diagram of the $\mathrm{BiFe}_{1-y} \mathrm{Sc}_{y} \mathrm{O}_{3}$ series in the range of $0.30 \leq y \leq 0.60$ demonstrates a good potential of controlled annealing of the metastable compositions to obtain materials with desired combinations of the perovskite phases.

Acknowledgments: This work was supported by project TUMOCS. This project has received funding from the European Union's Horizon 2020 research and innovation programme under the Marie Skłodowska-Curie grant agreement No 645660. 
Author Contributions: Edwin Eardley, Anatoli V. Pushkarev, and Yury V. Radyush prepared the precursors and preformed the high-pressure synthesis and phase characterization of the samples. Andrei N. Salak and Dmitry D. Khalyavin carried out in situ X-ray and neutron diffraction experiments, respectively. Nikolai M. Olekhnovich, Andrei N. Salak, and Dmitry D. Khalyavin analysed the data. Aleksandr D. Shilin and Vasili V. Rubanik assisted with the experiments and discussed the results. Andrei N. Salak coordinated the work and wrote the paper with the approval of all co-authors.

Conflicts of Interest: The authors declare no conflict of interest.

\section{References}

1. Silva, J.; Reyes, A.; Esparza, H.; Camacho, H.; Fuentes, L. BiFeO $\mathrm{B}_{3}$ : A review on synthesis, doping and crystal structure. Integr. Ferroelectr. 2011, 126, 47-59. [CrossRef]

2. Arnold, D.C. Composition-driven structural phase transitions in rare-earth-doped $\mathrm{BiFeO}_{3}$ ceramics: A review. IEEE Trans. Ultrason. Ferroelectr. Freq. Control. 2015, 62, 62-82. [CrossRef] [PubMed]

3. Olekhnovich, N.M.; Salak, A.N.; Pushkarev, A.V.; Radyush, Y.V.; Vyshatko, N.P.; Khalyavin, D.D.; Ferreira, V.M. Impedance spectroscopy of dielectric properties of perovskite ceramics $\mathrm{Bi}\left(\mathrm{Mg}_{1 / 2} \mathrm{Ti}_{1 / 2}\right) \mathrm{O}_{3}$. Phys. Solid State 2009, 51, 582-588. [CrossRef]

4. Suchomel, M.R.; Fogg, A.M.; Allix, M.; Niu, H.; Claridge, J.B.; Rosseinsky, M.J. Bi ${ }_{2} Z_{n T i O}$ : A lead-free closed-shell polar perovskite with a calculated ionic polarization of $150 \mu \mathrm{C} \mathrm{cm}^{-2}$. Chem. Mater. 2006, 18, 4987-4989. [CrossRef]

5. Delmonte, D.; Mezzadri, F.; Pernechele, C.; Calestani, G.; Spina, G.; Lantieri, M.; Solzi, M.; Cabassi, R.; Bolzoni, F.; Migliori, A.; et al. Thermally activated field-dependent magnetization reversal in bulk $\mathrm{BiFe}_{0.5} \mathrm{Mn}_{0.5} \mathrm{O}_{3}$. Phys. Rev. B 2013, 88, 014431. [CrossRef]

6. Delmonte, D.; Mezzadri, F.; Pernechele, C.; Gilioli, E.; Calestani, G.; Cabassi, R.; Bolzoni, F.; Spina, G.; Lantieri, M.; Solzi, M. Field effects on spontaneous magnetization reversal of bulk $\mathrm{BiFe}_{0.5} \mathrm{Mn}_{0.5} \mathrm{O}_{3}$, an effective strategy for the study of magnetic disordered systems. J. Phys. Condens. Matter 2015, $27,286002$. [CrossRef] [PubMed]

7. Delmonte, D.; Mezzadri, F.; Gilioli, E.; Solzi, M.; Calestani, G.; Bolzoni, F.; Cabassi, R. Poling-written ferroelectricity in bulk multiferroic double-perovskite $\mathrm{BiFe}_{0.5} \mathrm{Mn}_{0.5} \mathrm{O}_{3}$. Inorg. Chem. 2016, 55, 6308-6314. [CrossRef] [PubMed]

8. Inaguma, Y.; Katsumata, T. High pressure synthesis, lattice distortion, and dielectric properties of a perovskite $\mathrm{Bi}\left(\mathrm{Ni}_{1 / 2} \mathrm{Ti}_{1 / 2}\right) \mathrm{O}_{3}$. Ferroelectrics 2003, 286, 111-117. [CrossRef]

9. Suchomel, M.R.; Thomas, C.I.; Allix, M.; Rosseinsky, M.J.; Fogg, A.M.; Thomas, M.F. High pressure bulk synthesis and characterization of the predicted multiferroic $\mathrm{Bi}\left(\mathrm{Fe}_{1 / 2} \mathrm{Cr}_{1 / 2}\right) \mathrm{O}_{3}$. Appl. Phys. Lett. 2007, 90, 112909. [CrossRef]

10. Mandal, P.; Sundaresan, A.; Rao, C.N.R.; Iyo, A.; Shirage, P.M.; Tanaka, Y. Temperature-induced magnetization reversal in $\mathrm{BiFe}_{0.5} \mathrm{Mn}_{0.5} \mathrm{O}_{3}$ synthesized at high pressure. Phys. Rev. B 2010, 82, 100416. [CrossRef]

11. Khalyavin, D.D.; Salak, A.N.; Olekhnovich, N.M.; Pushkarev, A.V.; Radyush, Yu.V.; Manuel, P.; Raevski, I.P.; Zheludkevich, M.L.; Ferreira, M.G.S. Polar and antipolar polymorphs of metastable perovskite $\mathrm{BiFe}_{0.5} \mathrm{Sc}_{0.5} \mathrm{O}_{3}$. Phys. Rev. B 2014, 89, 174414.

12. Azuma, M.; Kanda, H.; Belik, A.A.; Shimakawa, Y.; Takano, M. Magnetic and structural properties of $\mathrm{BiFe}_{1-x} \mathrm{Mn}_{x} \mathrm{O}_{3}$. J. Magn. Magn. Mater. 2007, 310, 1177-1179. [CrossRef]

13. Azuma, M.; Niitaka, S.; Hayashi, N.; Oka, K.; Takano, M.; Funakubo, H.; Shimakawa, Y. Rhombohedraltetragonal phase boundary with high Curie temperature in $(1-x) \mathrm{BiCoO}_{3}-x \mathrm{BiFeO}_{3}$ solid solution. Jpn. J. Appl. Phys. 2008, 47, 7579-7581. [CrossRef]

14. Belik, A.A.; Rusakov, D.A.; Furubayashi, T.; Takayama-Muromachi, E. BiGaO 3 -based perovskites: A large family of polar materials. Chem. Mater. 2012, 24, 3056-3064. [CrossRef]

15. Rusakov, D.A.; Abakumov, A.M.; Yamaura, K.; Belik, A.A.; Van Tendeloo, G.; Takayama-Muromachi, E. Structural evolution of the $\mathrm{BiFeO}_{3}-\mathrm{LaFeO}_{3}$ system. Chem. Mater. 2011, 23, 285-292. [CrossRef]

16. Karimi, S.; Reaney, I.M.; Levin, I.; Sterianou, I. Nd-doped $\mathrm{BiFeO}_{3}$ ceramics with antipolar order. Appl. Phys. Lett. 2009, 94, 112903. [CrossRef] 
17. Levin, I.; Tucker, M.G.; Wu, H.; Provenzano, V.; Dennis, C.L.; Karimi, S.; Comyn, T.; Stevenson, T.; Smith, R.I.; Reaney, I.M. Displacive phase transitions and magnetic structures in Nd-substituted $\mathrm{BiFeO}_{3}$. Chem. Mater. 2011, 23, 2166-2175. [CrossRef]

18. Belik, A.A.; Abakumov, A.M.; Tsirlin, A.A.; Hadermann, J.; Kim, J.; Tendeloo, G.V.; Takayama-Muromachi, E. Structure and magnetic properties of $\mathrm{BiFe}_{0.75} \mathrm{Mn}_{0.25} \mathrm{O}_{3}$ perovskite prepared at ambient and high pressure. Chem. Mater. 2011, 23, 4505-4514. [CrossRef]

19. Salak, A.N.; Khalyavin, D.D.; Pushkarev, A.V.; Radyush, Yu.V.; Olekhnovich, N.M.; Shilin, A.D.; Rubanik, V.V. Phase formation in the $(1-y) \mathrm{BiFeO}_{3}-y \mathrm{BiScO}_{3}$ system under ambient and high pressure. J. Solid State Chem. 2017, 247, 90-96. [CrossRef]

20. Prosandeev, S.A.; Khalyavin, D.D.; Raevski, I.P.; Salak, A.N.; Olekhnovich, N.M.; Pushkarev, A.V.; Radyush, Yu.V. Complex antipolar $\sqrt{2} \times 4 \times 2 \sqrt{2}$ structure with Pnma symmetry in $\mathrm{BiFeO}_{3}$ and $\mathrm{BiFe}_{1 / 2} \mathrm{Sc}_{1 / 2} \mathrm{O}_{3}$ : First-principles calculations. Phys. Rev. B 2014, 90, 054110. [CrossRef]

21. Chapon, L.C.; Manuel, P.; Radaelli, P.G.; Benson, C.; Perrott, L.; Ansell, S.; Rhodes, N.J.; Raspino, D.; Duxbury, D.; Spill, E.; et al. Wish: The new powder and single crystal magnetic diffractometer on the second target station. Neutron News 2011, 22, 22-25. [CrossRef]

22. Rodriguez Carvajal, J. Recent advances in magnetic structure determination by neutron powder diffraction. Phys. B Condens. Matter 1993, 192, 55-69. [CrossRef]

23. Oka, K.; Koyama, T.; Ozaaki, T.; Mori, S.; Shimakawa, Y.; Azuma, M. Polarization rotation in the monoclinic perovskite $\mathrm{BiCo}_{1-x} \mathrm{Fe}_{x} \mathrm{O}_{3}$. Angew. Chem. Int. Ed. 2012, 51, 7977-7980. [CrossRef] [PubMed]

(C) 2018 by the authors. Licensee MDPI, Basel, Switzerland. This article is an open access article distributed under the terms and conditions of the Creative Commons Attribution (CC BY) license (http:/ / creativecommons.org/licenses/by/4.0/). 